\section{artelogie}

\section{Artelogie}

Recherche sur les arts, le patrimoine et la littérature de l'Amérique latine

$10 \mid 2017$

Après le paysage : l'art, l'inscription et la représentation de la nature en Amérique latine aujourd'hui

\title{
Entrevista com Luiz Marques, Professor da Universidade Estadual de Campinas, Brasil. Nossa tragédia pouco tem em comum com as tragédias passadas
}

Renato Menezes Ramos e Catalina Valdés

\section{OpenEdition \\ Journals}

\section{Edição electrónica}

URL: http://journals.openedition.org/artelogie/868

DOI: 10.4000/artelogie.868

ISSN: 2115-6395

Editora

Association ESCAL

\section{Refêrencia eletrónica}

Renato Menezes Ramos e Catalina Valdés, «Entrevista com Luiz Marques, Professor da Universidade Estadual de Campinas, Brasil. Nossa tragédia pouco tem em comum com as tragédias passadas », Artelogie [Online], 10 | 2017, posto online no dia 05 abril 2017, consultado o 15 setembro 2020. URL : http://journals.openedition.org/artelogie/868 


\title{
Entrevista com Luiz Marques,
} Professor da Universidade Estadual de Campinas, Brasil. Nossa tragédia pouco tem em comum com as tragédias passadas

\author{
Renato Menezes Ramos e Catalina Valdés
}

1 Luiz Marques é professor do Instituto de Filosofia e Ciências Humanas da Universidade Estadual de Campinas, onde ajudou a fundar o programa de pós-graduação em História da Arte. Em 1995 afastou-se desta instituição para assumir o cargo de curador-chefe do Museu de Arte de São Paulo (MASP), onde criou a Escola do MASP e organizou importantes mostras como as de Monet e Michelangelo. Desde muito cedo se tornou especialista em arte italiana, área na qual se destaca como maior autoridade no assunto em âmbito brasileiro. Consagrou sua tese de doutorado, defendida na École des Hautes Études en Sciences Sociales (EHESS), a Giotto. Ao longo de vinte anos, traduziu e comentou extensamente a biografia de Michelangelo escrita por Vasari, trabalho que lhe rendeu sua livre-docência, publicada em seguida em edição mais sucinta. Esteve à frente de diversos projetos de pesquisa e possui um grande número de artigos e livros, sempre dentro dos estudos da tradição clássica. Criou o MARE - Museu de Arte para a Educação, um banco de imagens comentadas por especialistas e também a Revista Figura - Studi sull'Immagini nella Tradizione Classica, cujos endereços de acesso seguem abaixo.

Desde alguns anos, a crise do capitalismo e o colapso ambiental despertaram em Luiz Marques um particular interesse, sobre o qual passou a trabalhar profundamente. Publicou em 2015 o livro "Capitalismo e Colapso Ambiental", revisto e ampliado no ano seguinte, e pelo qual recebeu recentemente o prêmio Jabuti na área de Ciências da Natureza, Meio Ambiente e Matemática.

3 A entrevista que segue procurou pensar um elemento imprescindível à paisagem enquanto gênero artístico, assim como o seu aspecto mais material: a natureza e o seu 
paulatino desfazimento. Luiz Marques demonstra, com a erudição que lhe é característica, a natureza expansionista do capitalismo, reflete sobre o modo como as instituições e os artistas atualmente incorporam este discurso em seus trabalhos, analisa os modos de construção do discurso ecológico pelas imagens e reivindica a urgência de pensar sobre este assunto que não escapa a absolutamente nenhum sujeito do mundo atual. As perguntas que ficam são garantidas pelo mistério que nelas se escondem: neste compasso de uso da natureza, onde iremos chegar? o que fazer para conter a tragédia do colapso ambiental? Em que grau o pensamento produzido pela arte e a experiência por ela engendrada dá conta da fatalidade do quadro que se desenha? A ausência de respostas equivale à grandeza e a urgência de tais perguntas, sobre as quais o professor refletiu mais longamente.

http://www.mare.art.br/

http://www.figura.art.br/

- O senhor dedicou a maior parte de sua trajetória profissional aos estudos em História da Arte, especialmente ao Renascimento Italiano, área na qual teve uma atuação notável e mesmo pioneira em âmbito nacional. Na última década, os seus interesses enquanto pesquisador deslocaram-se para o problema da crise do capitalismo e do colapso ambiental. Como aconteceu esse processo? O que há em comum entre essas duas faces do seu trabalho?

Há várias longas respostas à questão das razões desse meu "deslocamento". A resposta curta, e a melhor, vem na forma de outra pergunta: por que ainda tantos, na realidade a esmagadora maioria, não reservam às crises socioambientais a centralidade que elas impõem, haja vista sua extrema gravidade, sua aceleração e o que elas põem em jogo, a saber a sobrevivência das sociedades complexas e, no limite, da humanidade? Quanto mais procuro me informar e refletir sobre elas, mais me intriga o fato de que a maioria de nós ainda as considere como um problema entre outros.

Para responder à sua segunda questão, diria que se há algo em comum entre a arte e as crises socioambientais, é sua especularidade: a arte é o que mais convincentemente fala em favor do homem, ao passo que as crises socioambientais são em grande parte o fruto do que de mais desprezível e estúpido os homens têm em si: seu amor pelo capitalismo, pela expansão e pelo lucro.

- O Renascimento foi entendido como cosmovisão antropocêntrica, em que o indivíduo - o corpo e a vida individuais - eram a escala para o espaço e o tempo, e as ações humanas, motores da história. Hoje, utilizamos o termo Antropoceno para denominar uma mudança de era em que o fator de maior determinação sobre as dinâmicas ecológicas é a atividade da espécie humana. O senhor acredita que é possível estabelecer paralelos ou comparações entre os dois momentos?

Sim, por certo. No meu livro dediquei um capítulo (o capítulo 13) a essa questão. Ao longo do século XV, as famosas colunas de Hércules, marcos de um nec plus ultra que era ao mesmo tempo saber geográfico, fórmula de sapiência e advertência moral, perderam muito desse triplo significado. Carlos V inverteu seu significado antigo, quando, em outubro de 1516, Luigi Marliano forjou para o futuro imperador o mote: Plus Oultre. Nessa forma francesa, essa impresa conserva-se ainda no teto de seu palácio de Alhambra, em Granada, mas a divisa viria a se fixar já em 1518 na forma alemã, Noch Weiterer no retrato pintado por Hans Weidtiz, ou na forma latina mais habitual, Plus Ultra. É improvável, como argumenta Earl Rosenthal, que em 1516, a impresa de Carlos V já aludisse às colônias da Nova Espanha. Ela traduzia a ideia geral 
e abstrata de uma nova concepção da virtù, a qual consistia, doravante, no predomínio do ímpeto sobre a autocontenção, predomínio que doravante desafiava, recusava e se contrapunha abertamente à tradição antiga da sophrosyne, da phronesis e da prudentia. Esse ímpeto centrífugo podia se esquivar sem dificuldade da acusação de soberba já que seu álibi era a santa ambição de universalizar o Cristianismo, como num movimento de compensação pelas perdas sofridas no Mediterrâneo oriental. Mas ele não podia triunfar sobre o gentio sem sacrificar, para si próprio, ao menos duas das virtudes cardinais de matriz platônica acolhidas pela teologia cristã: a prudência e a temperança.

Se a Idade Moderna, que se consolida, a meu ver, com a Reforma e a definitiva dominação hispano-habsbúrgica sobre a Itália a partir do terceiro decênio do século XVI, pode ser justamente chamada "moderna", é porque com ela se afirma o imperativo das forças centrífugas sobre as forças centrípetas das civilizações da Antiguidade, umbilicalmente ligadas ao Mediterrâneo. Nada resta do sentido restaurador de uma ordem transgredida, típica da épica antiga, na epopeia ibérica. A matéria d'Os Lusíadas de Camões não evoca a reparação de uma transgressão como a de Páris, o retorno a casa como o de Ulisses ou um mito de origem como a fundação de Roma. O que o poema canta é, de fato, a superação da Antiguidade, e desde logo nos celebérrimos versos do seu exórdio:

Cessem do sábio grego e do Troiano As navegações grandes que fizeram;

Cale-se de Alexandre e de Trajano

A fama das vitórias que tiveram;

Que eu canto o peito ilustre Lusitano,

A quem Neptuno e Marte obedeceram.

Cesse tudo o que a Musa antiga canta,

Que outro valor mais alto se alevanta.

- O problema da sustentabilidade e da relação homem-natureza foi o tema central dos Jogos Olímpicos RIO 2016, presente desde a cerimônia de abertura. Assim, este evento constitui o capítulo mais recente de uma longa tradição, não apenas brasileira, mas latinoamericana, que assimila a natureza como elemento central da sua constituição identitária. Há nisto, porém, um imenso descompasso, se pensarmos como vêm se dando as políticas ambientais na América Latina. Como o senhor vê a contradição entre o idílio de natureza virgem e exuberante propagandeado e a realidade econômica de uma América Latina como fonte finita de recursos naturais?

Não encontro muitos elementos que confirmem essa ideia de que a natureza é um elemento central da constituição identitária no Brasil (não generalizo para a América Latina porque nada sei a respeito). Há, por certo, o "momento" nativista do Romantismo brasileiro, parodiado em chave supostamente irônica pelo Modernismo. Mas José de Alencar sempre foi considerado intelectualmente "ingênuo", e com frequência a ideia da emancipação da cultura brasileira baseia-se na tese da "superação" de Alencar por Machado de Assis. Em suma, salvo melhor juízo, esses momentos nativistas parecem mais periféricos que constitutivos. Claro, há Guimarães Rosa. Mas se trata de um gênio isolado, e ademais para ele o sertão-cosmos nada tem, absolutamente nada, de "identitário" em sentido nacional.

O que vejo prevalecer no Brasil é o sentimento de que a natureza é algo précivilizatório, é o estigma da incipiência e do atraso da nossa sociedade. A natureza 
precisa ser "vencida" para que nos tornemos, enfim, civilizados. Esse lugar-comum reaparece pela enésima vez quando a Amazônia começa a ser eviscerada por um número crescente de rodovias durante a ditadura. Não esqueçamos o grotesco da placa descerrada por Garrastazu Médici (dos ditadores brasileiros o mais violento, o mais glorificado em seus dias pela grande imprensa e o que tem as mãos mais sujas de sangue), quando da cerimônia de início da construção da rodovia Transamazônica, em 9 de outubro de 1970: "Nestas margens do Xingu, em plena selva amazônica, o Sr. Presidente da República dá início à construção da Transamazônica, numa arrancada histórica para a conquista deste gigantesco mundo verde“. A Amazônia sempre foi isso para o positivismo militar brasileiro e não apenas para ele: um gigantesco mundo verde a ser conquistado, posto que "vazio", como se ela não fosse ocupada e preservada há milênios pelos povos da floresta. Os "conquistadores" estão finalmente conseguindo seu intento: devastar a floresta, substituí-la por commodities e reduzir um dos mais maravilhosos biomas do planeta a algo que não sabemos ainda o que será. Na melhor das hipóteses, uma savana em vias de aridificação ou mesmo, no limite, de desertificação.

Já o discurso supostamente ecológico dos JO de 2016 pertence à retórica da COP21 e é algo típico da "espetacularização" da ecologia. Teria sido mais honesto e efetivo despoluir a Baía da Guanabara e a Lagoa Rodrigo de Freitas, do que nos colocar retoricamente "em dia" com o mundo. O Brasil, um dos países mais conservadores do mundo, sempre se adaptou às pressões modernizadoras externas, sem de fato se modernizar.

- Com o tema "Incerteza viva", a Bienal de São Paulo de 2016 propõe que se pense "as condições de vida atuais e as estratégias oferecidas pela arte contemporânea para acolher ou habitar incertezas". Em sua opinião, qual é o lugar do artista hoje? E, ampliando o escopo da pergunta, que função cumpre os dispositivos de exibição de arte?

Impossível propor respostas à altura da complexidade das duas perguntas. Não sei qual é lugar do artista hoje. Mas seria talvez mais crucial se perguntar qual é o lugar da arte hoje. Qualquer que seja, ele é certamente muito menos "necessário" do que o foi no passado. Quanto à Bienal, não a visitei ainda, mas a ideia de que devamos "acolher ou habitar incertezas" parece-me do mais cândido otimismo. Ninguém é profeta e se a história, notadamente a contemporânea, nos ensinou algo é a vanidade de toda filosofia da história que se arroga a presunção de prevê-la. Isso posto, há um consenso científico extremamente consolidado e todo um corpo de evidências empíricas apontando convergentemente para um futuro seguramente muito pior que o presente. Mantida a trajetória de colapso ambiental em que estamos, não é mais razoável cultivar incertezas sobre o que já estamos vivendo e sobre o que nos aguarda num futuro muito próximo. Seria mais útil e lúcido partir dessa certeza (fornecida pela melhor ciência atualmente disponível), do que apelar para a suposta vitalidade da incerteza.

- Pensando na crise do capitalismo tratada no seu livro mais recente, o senhor vê a possibilidade de estabelecer aproximações entre a diminuição drástica de biodiversidade e as práticas culturais, que aparentemente também perdem diversidade?

De novo, sua questão é desencorajadoramente complexa. Há pelo menos um século discute-se e se faz de certo modo o luto da "crise do espírito", do declínio e mesmo do colapso da civilização ocidental. De 1918 a 1953, numerosas obras filosóficas, sociológicas e históricas, bem como de literatura e artes visuais, têm por eixo comum 
a percepção de declínio civilizacional causado sobretudo pelo débâcle da Europa. Recordem-se, apenas a título de exemplo: 1918 - Oswald Spengler, Der Untergang des Abendlands (O declínio do Ocidente); 1919 - Paul Valéry, La crise de l'esprit; 1919 Sigmund Freud, Das Unheimliche; 1920 - Albert Démangeon, Le déclin de l'Europe; 1921 Arnold Toynbee, Study of History (projeto inicial); 1923 - Francesco Nitti, La tragedia dell'Europa; 1924 - Thomas Mann, Der Zauberberg (A Montanha Mágica); 1925 - T.S. Eliot, The Hollow Men; 1927 - Sigmund Freud, Die Zukunft einer Illusion (O Futuro de uma Ilusão); 1930 - Sigmund Freud, Das Unbehagen in der Kultur (O Mal-estar na civilização); 1934/1941 - Stephan Zweig, Die Welt von Gestern. Erinnerungen eines Europäers ("O Mundo de Ontem. Recordações de um Europeu"); 1935 - Johan Huizinga, In the Shadow of Tomorrow; 1943/1947 - Thomas Mann, Doktor Faustus; 1947 - W. H. Auden,"The Age of Anxiety“; 1953 - Martin Heidegger, Die Frage nach der Technik (A questão da técnica) etc. Isso sem contar toda a crítica da indústria cultural levada a cabo pela Escola de Frankfurt. Temos, portanto, uma longa e rica tradição de reflexão intelectual e artística sobre o declínio das práticas culturais, tão longa e tão rica, que é talvez paradoxal falar em declínio.

Isso posto, é preciso atentar para a diferença essencial existente entre essa problemática cultural ou artística e a questão existencial com a qual nos defrontamos hoje. $O$ que é próprio dos nossos dias não se restringe a um declínio ou a um colapso de cunho civilizacional stricto sensu, isto é, a um memento mori sobre a finitude das civilizações, tal como tematizado no primeiro pós-guerra pela chamada crítica da civilização (Zivilizationskritik), no rastro dos grandes pensadores e artistas acima evocados. O que nos ameaça agora é um colapso ambiental, isto é, um colapso que ocorre no nível mais amplo da biosfera, sendo as sociedades humanas apenas uma instância particular dessa esfera. A dimensão dessa crise não tem, portanto, precedentes históricos em nossa cultura e nem mesmo na história da nossa jovem espécie. A contradição maior de nosso tempo é, se não me abuso, o fato que, de um lado, tendemos naturalmente a pensar e reagir politicamente aos desafios atuais a partir do repertório das experiências artísticas, culturais e políticas que nos foi legado e que constitui nossa memória. Mas, de outro lado, esse repertório não contém, e não teria por que conter, os elementos que nos permitiriam pensar e reagir politicamente a esses desafios. Nossa tragédia, em suma, pouco tem em comum com as tragédias passadas. Aquelas, bem ou mal, superamos, como prova o fato de estarmos aqui. Ninguém sabe se e como superaremos a atual.

Convidamos, por fim, o professor Luiz Marques a comentar uma imagem de sua escolha, que dialogasse, em alguma medida, com o que foi abordado ao longo das perguntas, seja por meio de ratificações, seja por meio de ausências e eminências. 
Pedro Martinelli, Raposa morta na estrada P158, região da Serra dos Carajás, Pará, 1997

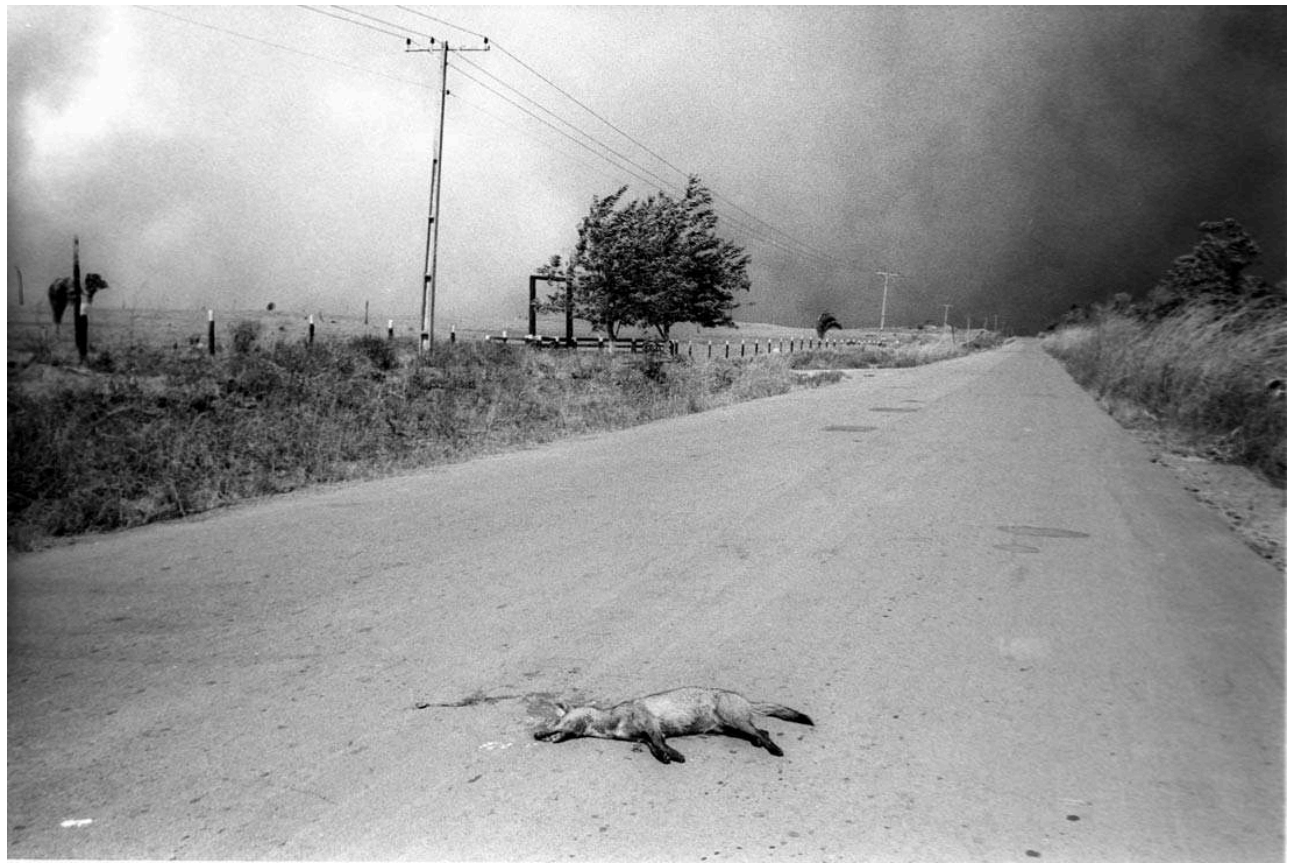

Publicadas no livro Amazônia O Povo das Águas (São Paulo: Terra Virgem Editora, 2000). http:// www.pedromartinelli.com.br/blog/wp-content/uploads/2010/10/aaaa13.jpg

Esta é uma imagem de uma eloquência e de uma crueza brutais. Salvo raras exceções (Anselm Kiefer e pouquíssimos outros), há tempos a arte perdeu sua potência, sua capacidade de guardar para si o lugar do "negativo" na tensão entre real e consciência; há tempos, se esmera em (ou desistiu de) ser mais audaz, mais dolorosamente lúcida, acusatória e atroz que o humilde gênero "documentário"... 